\title{
Determination of antioxidant and antimicrobial activities of leaf extracts of Otostegia integrifolia
}

\author{
Yiketel Adege Chekol and Zelalem Yibralign Desta*
}

\begin{abstract}
Background: The extracts from the leaves of Otostegia integrifolia have been reported to show phytochemical analysis, total flavonoid content, antioxidant and antibacterial activities.

Results: Our results revealed that the total flavonoid content of methanol and ethyl acetate extracts is $416.5+0.288$ and $248.9+0.872 \mathrm{mgAAE} / 100 \mathrm{~g}$ respectively. The two extracts also showed good antioxidant activity as well as weak to moderate antibacterial activity against some bacteria.

Conclusions: The leaf extracts from O. integrifolia showed good total flavonoid content, DPPH radical scavenging activity and antibacterial activity. In addition to this, the extracts also showed the presence of some important compounds by phytochemical analysis.
\end{abstract}

Keywords: Otostegia integrifolia, Flavonoid content, Antioxidant activity, Antibacterial activity

\section{Background}

Otostegia integrifolia, more commonly known as Abyssinian rose, a plant belonging to the family Lamiaceae, is endemic to Ethiopia, in the dry evergreen woodlands of the Tigray, Gondar, Wollo, Gojjam, North Shewa, Kaffa and Hararghe regions, as well as in the dry and moist agro climatic zones of the district known as Dega [1]. The plant is also endemic to Eritrea and Yemen [2]. Otostegia integrifolia is a shrub which grows up to $3 \mathrm{~m}$ tall, often with paired spines at the nodes. Its leaves are sessile or shortly petiolate. The blade is bluish greyish-green, oblanceolate to lanceolate shaped, and reaches $2-9 \mathrm{~cm}$ long $[3,4]$. The plant grows in the wild but is also cultivated in gardens. It grows on mountain bush lands and wood lands over grazed slopes at altitudes ranging from 1300 to $2800 \mathrm{~m}$. In Ethiopian traditional medicine, the leaves of O. integrifolia are used for the treatment of several diseases including malaria, for treatment of ophthalmia, as an anti-microbial, antihyperglycemic, and for its anti-oxidant properties used in preventing different kinds

\footnotetext{
*Correspondence: yibrazelalem@yahoo.com Department of Chemistry, College of Science, Bahir Dar University, P. O. Box 79, Bahir Dar, Ethiopia
}

of sickness and disorders [5]. In this paper we reported phytochemical analysis, total flavonoid content, antioxidant and antibacterial activities of $O$. integrifolia leaf extracts.

\section{Results and discussion}

The results of phytochemical analysis, total flavonoid content, antioxidant activity and antimicrobial activity tests obtained from different extracts of the leaves of $O$.

\section{Phytochemical analysis}

This study showed the presence of different bioactive compounds in different solvent extracts of the leaves of O. integrifolia by using color change as a confirmatory test. Methanol extract was found to have a wide range of bioactive compounds including flavonoids, phenols, terpenoids, saponins, steroids and glycosides because of its high polarity. The ethyl acetate extract was also positive for flavonoids, phenols, terpenoids, saponins, steroids and glycosides since ethyl acetate has medium polarity. The petroleum ether being highly non-polar in nature and was able to extract very limited compounds 
such as steroids and glycosides. Alkaloids and tannins were however absent in all extracts of the leaf parts of the plant. The result of the test was summarized as follows in Table 1.

\section{Determination of the total flavonoid content}

The total flavonoid content of the extracts expressed as quercetin equivalent (mgQE) per dry sample (Table 2). As it was observed from the table, both methanol and ethyl acetate extracts of the leaves of O. integrifolia were contain flavonoids. The total flavonoid content of methanol extract was $416.5+0.288 \mathrm{mgQE} / 100 \mathrm{~g}$ dry sample while that of ethyl acetate extract was $248.9+0.872 \mathrm{mgQE} / 100 \mathrm{~g}$ dry sample which mean methanol extract contains more flavonoids compared to ethyl acetate extract.

\section{Antioxidant activity}

The antioxidant activities of the extracts of the leaves of $O$. integrifolia were evaluated by using FRAP and DPPH assays.

\section{Ferric reducing antioxidant power (FRAP) assay}

In this method, ascorbic acid was used as a standard to determine antioxidant activities of the extracts of the leaves of $O$. integrifolia. From Table 3, we observed that methanol extract has higher mgAAE/100 g dry weight i.e., $286.146+0.889 \mathrm{mgAAE} / 100 \mathrm{~g}$ dry weight than ethyl acetate extract i.e., $219.496+0.566 \mathrm{mgAAE} / 100 \mathrm{~g}$ dry weight, that can strengthen the greater reducing power of methanol extract. The result of our study for each extract was supported by previous reported data by Anwar et al. [6] and this report revealed that the extracts of more polar solvents exhibited better antioxidant activities than that of less polar solvents.

Table 1 Qualitative analysis of phytochemicals present in leaf extracts of $O$. integrifolia

\begin{tabular}{llll}
\hline Phytochemicals & ME & EA & PE \\
\hline Alkaloids & - & - & - \\
Flavonoids & ++ & + & - \\
Phenols & + & + & - \\
Tannins & - & - & - \\
Steroids & + & + & + \\
Saponins & + & + & - \\
Terpinoids & + & ++ & - \\
Glycosides & ++ & ++ & + \\
\hline
\end{tabular}

$(++)$ highly present, $(+)$ present, $(-)$ not present

$M E$ methanol extracts, $E A$ ethyl acetate extract, $P E$ petroleum ether extract
Table 2 Total flavonoid content of leaf extracts of $\boldsymbol{O}$. integrifolia

\begin{tabular}{lll}
\hline Extracts & Absorbance at 510 & $\begin{array}{l}\text { mgQE/100 g of dry } \\
\text { weight }\end{array}$ \\
\hline Methanol extract & $0.148 \pm 0.0009$ & $416.5 \pm 0.288$ \\
Ethyl acetate extract & $0.092 \pm 0.0029$ & $248.9 \pm 0.872$ \\
\hline
\end{tabular}

Data expressed as mean of three determinations \pm standard deviation

\section{DPPH radical scavenging activity}

The DPPH free radical scavenging ability of the extracts of the leaves of $O$. integrifolia was expressed using mgAAE/100 g of dry sample. The DPPH free radical scavenging ability of methanol and ethyl acetate extracts were evaluated by using color change as the reagent was added and recorded the absorbance of each extracts at different concentrations. The change of a color from pink to yellow in each extracts as well as standard solution confirmed that they have DPPH radical scavenging capacity. The faster the disappearance of the color revealed that the extract has higher DPPH free radical scavenging activity. According to our study, methanol extract showed change of the color from pink to yellow faster than that of ethyl acetate extract, then methanol extract has greater DPPH radical scavenging power compared to that of ethyl acetate extract as shown in Table 4.

\section{Antibacterial activity}

Antibacterial activity of the extracts of the leaf of $O$. integrifolia was evaluated by using Agar well diffusion method. Five bacteria were used for the determination in which three of them were gram negative bacteria (E. coli, S. typhi and K. pneumoniae) whereas the remaining two were gram positive bacteria (S. aurous and S. pyogens). As shown in Table 5, methanol extract showed a significant antibacterial activity whereas there was no inhibition zone recorded in petroleum ether extract in all five bacteria. Ethyl acetate extract had also a potential antibacterial activity against all five bacteria except $S$. aurous. All extracts had lowest antibacterial potential as compared to standards (Gentamycin and Chloramphenicol). In this study a good antibacterial activities were recorded using methanol extract compared to other extracts. For instance, methanol extract showed a good antibacterial

Table 3 FRAP values of leaf extracts of 0 . integrifolia (mgAAE/100 g)

Extracts

FRAP value in $\mathrm{mg} A A E / 100 \mathrm{~g}$ dry wt

Methanol extract

$286.146 \pm 0.889$

Ethyl acetate extract

$219.496 \pm 0.566$ 
Table 4 DPPH radical scavenging values of leaf extracts of $O$. integrifolia

\begin{tabular}{ll}
\hline Extracts & $\begin{array}{l}\text { DPPH scavenging value (mg } \\
\text { AAE/100 } \mathbf{g} \text { of dry weight) }\end{array}$ \\
\hline Methanol extract & $82.91 \pm 0.365$ \\
Ethyl acetate extract & $32.68 \pm 1.545$ \\
\hline
\end{tabular}

result against $S$. aureus, E. coli and S. typhi with minimum zone of inhibition $13.5+0.40,13.9+0.16$ and $10.1+0.04$ respectively however, the highest minimum inhibition zone was recorded in ethyl acetate extract against $S$. pyogens and $K$. pneumoniae with minimum zone of inhibition $17.1+0.14$ and $16.8+0.41$ respectively.

\section{Experimental section}

\section{Chemicals and reagents}

Ferric chloride $\left(\mathrm{FeCl}_{3}\right)$, Wagner's reagent (Iodine in potassium iodide), hydrated aluminum chloride $\left(\mathrm{AlCl}_{3} \cdot 6 \mathrm{H}_{2} \mathrm{O}\right)$, sodium nitrite $\left(\mathrm{NaNO}_{2}\right)$, hydrochloric acid, sulfuric acid $\left(\mathrm{H}_{2} \mathrm{SO}_{4}\right)$, sodium hydroxide $(\mathrm{NaOH})$, nitric acid $\left(\mathrm{HNO}_{3}\right)$, sodium carbonate $\left(\mathrm{NaCO}_{3}\right)$, monosodium hydrogen phosphate $\left(\mathrm{NaH}_{2} \mathrm{PO}_{4}\right)$, disodium hydrogen phosphate $\left(\mathrm{Na}_{2} \mathrm{HPO}_{4}\right)$, trichloroacetic acid, potassium hexacyanoferrate (II) $\left(\mathrm{K}_{2}\left[\mathrm{Fe}(\mathrm{CN})_{6}\right]\right.$, Ascorbic acid, 2,2-diphenyl1-picrylhydrazyl (DPPH), quarticien, ammonia solution, chloroform, acetone, iodine powder, potassium iodide, Muller Hinton agar, ethyl acetate, methanol, petroleum ether, distilled water and deionized water were some of the chemicals and reagents that were used for the experimental work during our study.

\section{Plant materials}

Fresh leaves of $O$. integrifolia were collected from Arebaya, which is located in north Gonder zone and $288 \mathrm{~km}$ away from Bahir Dar, Amhara regional state, Ethiopia in May 2017. The plant material was identified and authenticated by Dr. Ali Seidu, botanist in biology department, Bahir Dar University.

\section{Extraction of samples}

The air-dried and ground $(100 \mathrm{~g})$ of the leaves of $O$. integrifolia were extracted by soaking successively in $n$-hexane, ethyl acetate (EtOAc) and methanol $(\mathrm{MeOH})$ each for $24 \mathrm{~h}$ (two times with each solvent) and removal of the solvent under reduced pressure using a BUCHI flash evaporator to afford extracts of $2.1 \mathrm{~g}$ (for $n$-hexane), $13.0 \mathrm{~g}$ (for EtOAc) and $18.5 \mathrm{~g}$ (for $\mathrm{MeOH}$ ).

\section{Phytochemical analysis}

The phytochemical analysis of methanol, ethyl acetate and petroleum ether extracts of the leaves of O. integrifolia were studied by slight modifications based on standard procedures described on different literatures [7-10].

\section{Measurement of total flavonoid content}

Total flavonoid content was measured with aluminum chloride colorimetric assay as described by different researchers with minor modifications $[10,11]$. In brief, $1 \mathrm{~mL}$ of methanol and ethyl acetate extracts and $1 \mathrm{~mL}$ of standard quercetin solutions $(20,40,60,80 \mu \mathrm{g} / \mathrm{mL})$ were positioned into test tubes and $4 \mathrm{~mL}$ of distilled water and $0.3 \mathrm{~mL}$ of $5 \%$ sodium nitrite solution were

Table 5 Comparison of MZI among leaf extracts of $O$. integrifolia

\begin{tabular}{|c|c|c|c|c|c|c|}
\hline \multirow[t]{2}{*}{ Extracts and standard antibiotics } & \multirow[t]{2}{*}{ Concentration in $\mu \mathrm{g} / \mathrm{mL}$} & \multicolumn{5}{|c|}{ Average values of zone of inhibition } \\
\hline & & S. aurous & S. pyogens & E. coli & S. typhi & K. pneumoniae \\
\hline \multirow[t]{4}{*}{ Methanol extract } & 25 & $11.4 \pm 0.29$ & $14.6 \pm 0.25$ & $8.5 \pm 0.09$ & $9 . .3 \pm 0.03$ & $6.4 \pm 0.21$ \\
\hline & 50 & $11.7 \pm 0.37$ & $15.0 \pm 0.36$ & $9.7 \pm 0.59$ & $9.9 \pm 0.16$ & $7.6 \pm 0.29$ \\
\hline & 75 & $12.2 \pm 0.33$ & $15.3 \pm 0.33$ & $11.1 \pm 0.37$ & $10.1 \pm 0.04$ & $10.3 \pm 0.43$ \\
\hline & 100 & $13.5 \pm 0.40$ & $15.7 \pm 0.26$ & $13.9 \pm 0.16$ & $10.1 \pm 0.38$ & $12.2 \pm 1.03$ \\
\hline \multirow[t]{4}{*}{ Ethyl acetate extract } & 25 & 0 & $10.4 \pm 0.17$ & $6.6 \pm 0.12$ & $6.4 \pm 0.05$ & $12.6 \pm 0.24$ \\
\hline & 50 & 0 & $11.6 \pm 0.34$ & $7.1 \pm 0.17$ & $6.9 \pm 0.16$ & $13.4 \pm 0.34$ \\
\hline & 75 & 0 & $15.5 \pm 0.1$ & $7.8 \pm 0.29$ & $8.6 \pm 0.28$ & $14.8 \pm 0.26$ \\
\hline & 100 & 0 & $17.1 \pm 0.14$ & $8.6 \pm 0.21$ & $9.4 \pm 0.49$ & $16.8 \pm 0.41$ \\
\hline \multirow[t]{4}{*}{ Petroleum ether extract } & 25 & 0 & 0 & 0 & 0 & 0 \\
\hline & 50 & 0 & 0 & 0 & 0 & 0 \\
\hline & 75 & 0 & 0 & 0 & 0 & 0 \\
\hline & 100 & 0 & 0 & 0 & 0 & 0 \\
\hline \multirow[t]{2}{*}{ Standard antibiotics } & Gen. & $24.5 \pm 0.12$ & $27.7 \pm 0.08$ & $25.0 \pm 0.12$ & $23.4 \pm 0.37$ & $23.1 \pm 0.33$ \\
\hline & Chl. & $18.8 \pm 0.21$ & $31.4 \pm 0.15$ & $16.6 \pm 0.17$ & $15.5 \pm 0.21$ & $19.8 \pm 0.13$ \\
\hline
\end{tabular}

S. aureus, Staphylococcus aureus; S. pyogens, Streptococcus pyogens; E. coli, Escherichia coli; S. typhi, Salmonella typhi; K. pneumoniae, Klebsiella Pneumoniae; Gen, Gentamycin; Chl, Chloramphenicol 
added into each solutions. After $5 \mathrm{~min}, 0.3 \mathrm{~mL}$ of $10 \%$ aluminum chloride was added. At 6 th min, $2 \mathrm{~mL}$ of $1 \mathrm{M}$ sodium hydroxide was added and orange yellowish color was developed. The absorbance was measured at $510 \mathrm{~nm}$ by using UV-visible spectrophotometer. The blank was performed using distilled water. Quercetin was used as standard. The samples were performed in triplicates. The calibration curve was plotted using standard quercetin. The data of the total flavonoid contents was expressed as mg of quercetin equivalents/100 g of dry mass.

\section{Measurement of free radical scavenging activity $D P P H$ radical scavenging assay}

The antioxidant activity of methanol and ethyl acetate extracts was measured on the basis of the scavenging activity of the stable 1,1-diphenyl-2-picrylhyorazyl (DPPH) free radical according to the method described by Thaiponga et al. with slight modifications $[10,12,13]$. In brief, $1 \mathrm{~mL}$ of DPPH solution was added to $4 \mathrm{~mL}$ of various concentrations of methanol and ethyl acetate extracts and ascorbic acid to be tested. After $30 \mathrm{~min}$, absorbance was measured at $517 \mathrm{~nm}$. Ascorbic acid with a series of concentration was used as a reference material. All tests were performed in triplicate.

\section{Ferric reducing antioxidant power (FRAP) assay}

The reducing power of methanol and ethyl acetate extracts was determined according to the method described by Abebe et al. [13] with slight modification [13]. In brief, $2.5 \mathrm{~mL}$ of different concentration of methanol and ethyl acetate extracts were mixed with $2.5 \mathrm{~mL}$ of phosphate buffer solution $(\mathrm{PH}=6.6,0.2 \mathrm{M})$ and $2.5 \mathrm{~mL}$ of potassium hexacyanoferrate $\left(\left[\mathrm{K}_{3} \mathrm{Fe}(\mathrm{CN})_{6}\right]\right)(1 \%)$. The mixture was incubated at $50{ }^{\circ} \mathrm{C}$ for $20 \mathrm{~min}$ in water bath. Then $2.5 \mathrm{~mL}$ of Trichloroacetic acid (10\%) was added to the mixture to terminate the reaction. $5 \mathrm{~mL}$ of the upper layer of the solution was mixed with $5 \mathrm{~mL}$ of distilled water and $0.5 \mathrm{~mL}$ of $\mathrm{FeCl}_{3}$ solution $(0.1 \%)$. The reaction mixture was leave for $10 \mathrm{~min}$ at room temperature and the absorbance developed bluish green color was measured at $700 \mathrm{~nm}$ by using UV-spectrophotometer against a blank solution. Distilled water was used instead of extracts or standard to prepare a blank solution.

\section{Antimicrobial activity}

Antimicrobial activities were performed in microbiology laboratory, department of Biology, Bahir Dar University by using agar well diffusion method. Muller Hinton agar media was prepared for culturing selected gram negative and gram positive bacteria by using standard methods. Five bacteria [two gram positive ( $S$. aureus and S. pyogens) and three gram negative (E. coli, S. typhi and $K$. pneumoniae)] were selected and collected from department of Biology, Bahir Dar University. A series of plant extract concentrations $(25,50,75,100 \mu \mathrm{g} / \mathrm{mL})$ and standard antibiotics (Gentamycin and Chloramphenicol) were added to the incubated plate by using filter paper. Then it was incubated for $24 \mathrm{~h}$ at $37^{\circ} \mathrm{C}$ and the experiment was repeated three times, and average values of zone of inhibition was recorded in $\mathrm{mm}$ for antimicrobial activity as described before $[14,15]$.

\section{Data analysis}

The results were reported as mean \pm standard deviation (SD). The calibration curves were constructed by using Microsoft excel window 10 and origin 8.

\section{Conclusions}

In conclusion, we found that the leaf extracts from $O$. integrifolia showed good total flavonoid content, good DPPH radical scavenging activity and weak to moderate antibacterial activity. Among those extracts, methanol extract is the one that showed good activities compared to that of ethyl acetate and petroleum ether extracts.

\section{Authors' contributions}

ZYD was supervised the whole work as well as organized the manuscript as a whole and YAC did theexperiment. All authors contributed to manuscript finalization. All authors read and approved the final manuscript.

\section{Acknowledgements}

We would like to thank Bahir Dar University for financial support to do this research. Yiketel Adege Chekol also thanks ministry of education, Ethiopia for study leave.

\section{Competing interests \\ The authors declare that they have no competing interests.}

Availability of data and materials

The authors have the samples.

Consent for publication

All authors consent to the publication.

Ethics approval and consent to participate

All authors declare that they have ethics approval and consent to participate.

\section{Funding}

Waiver.

\section{Publisher's Note}

Springer Nature remains neutral with regard to jurisdictional claims in published maps and institutional affiliations.

Received: 10 November 2017 Accepted: 9 May 2018

Published online: 18 May 2018

References

1. Sebald O (2006) Otostegia benth. In: Hadberg I, Kelbessa E, Edward S, Demissew $S$ (eds) Flora of Ethiopia and eritrea from gentianaceae to cyclocheilaceae, vol 5. National Herbarium, Addis Ababa University, Addis Ababa, p 538 
2. Al-Musayeib NM, Abbas FA, Ahmad MS, Mossa JS, El-Feraly FS (2000) Labdane diterpenes from Otostegia fruticosa. Phytochemistry 54:771-776

3. Ayatollahi SAM, Kobarfard F, Asgarpanah J, Ahmed Z (2007) Chemical constituents of O. perisca. J Chem Soc Pak 29:61-63

4. Tofighi ZF, Yassa AN, Goodarzy SR (2009) Chemical composition and antioxidant activity of Otostegia persica essential oil from Iran. Int J Essent Oil Ther 3:45-48

5. Sadia NU, Afsar SK, Rizwana SN (2014) Physiochemical screening and antimicrobial potential of Otostegia limbata Benth. J Chem Soc Pak 36:685-688

6. Anwar F, Bushra S, Muhammad A (2009) Effect of extraction solvent/technique on the antioxidant activity of selected medicinal plant extracts. Molecules 14:2167-2180

7. Osibemhe M, Onoagbe IO (2015) Qualitative and quantitative phytochemical evaluations of Strophanthus hispidus stem bark. J Pharm Biol Sci 10:120-124

8. Ram S, Sinha VS (2015) Qualitative phytochemical analysis of some plants uses to cure malaria in Kolhan region of Jharkhand, India. J Med Plants Stud 3:60-62
9. Kamala PK, Narendra DS (2014) Studies on qualitative and quantitative phytochemical analysis and screening of in vitro biological activities of Leucas indica (L.) VAR. Int J Herbal Med 2:30-36

10. Prashant T, Bimlesh K, Mandeep K (2011) Phytochemical screening and extraction. Internationale Pharmaceuticasciencia 1:99-105

11. Rohan SP, Anup SH (2014) Total antioxidant capacity (TAC) of fresh leaves of Kalanchoe pinnata. J Pharm Phytochem 2:32-35

12. Enujiugha VN, Talabi JY, Malomo SA, Olagunju AI (2012) DPPH radical scavenging capacity of phenolic extracts from African yam bean (Sphenostylis stenocarpa). Food Nutr Sci 3:7-13

13. Abebe A, Abebe M, Mekonnen A (2017) Assessment of antioxidant and antibacterial activities of crude extracts of Verbena officinalis linn root or atuch (Amharic). Chem Int 3:172-184

14. Lalas S, Gortzi O, Athanasiadis V, Tsaknis J, Chinou I (2012) Determination of antimicrobial activity and resistance to oxidation of Moringa peregrina seed oil. Molecules 17:2330-2334

15. Naz S, Farooq U, Khan A, Khan S (2014) Physiochemical screening and antimicrobial potentisal of Otostegia limbata benth. J Chem Soc Pak 36:683-686

\section{Submit your manuscript to a SpringerOpen ${ }^{\circ}$ journal and benefit from:}

- Convenient online submission

- Rigorous peer review

- Open access: articles freely available online

- High visibility within the field

- Retaining the copyright to your article

Submit your next manuscript at $\boldsymbol{\nabla}$ springeropen.com 